\title{
A compreensão da vida e da arte de Mário de Andrade: suas cartas
}

Ieda Lebensztayn

\author{
"Mas há um ouvido mais fino que escuta, \\ um peito de artista que incha, e uma rosa se abre, \\ um segredo comunica-se, o poeta anunciou, \\ o poeta, nas trevas, anunciou."
}

O OUVIDO mais fino que escuta e o peito de artista que incha: o olhar para o outro social e a expressão dos impasses subjetivos com consciência crítica constituem o ideal de arte de Mário de Andrade revelado e realizado em $A$ rosa do povo. Os versos citados são de "Mário de Andrade desce aos infernos", poema escrito por Carlos Drummond de Andrade (1964a, p.211) quando o amigo morreu do coração, em fevereiro de 1945.

À semelhança de Drummond, e de Ricardo Ramos ao construir o Retrato fragmentado do pai começando da morte de Graciliano, é também da morte de Mário que Marcos Antonio de Moraes parte ao tecer sua bela compreensão da obra epistolográfica do escritor modernista: Orgulho de jamais aconselhar.

Empreendida por Marcos de Moraes no início do primeiro capítulo do livro ("Persona, Personagens"), a reconstituição dos últimos dias de Mário de Andrade provoca pungência e exerce um papel crítico, à medida que delineia a vasta dimensão dos projetos intelectuais vividos intensamente pelo escritor. Preocupado com o trabalho no Conservatório, as perspectivas de Mário à época eram: terminar $O$ seqüestro da dona ausente, aprofundar seu estudo da poesia de Bandeira, Drummond e Murilo Mendes (em $O$ pico dos três irmãos), retomar os estudos de folclore musical, além de permanecer dedicado à prática epistolográfica. E ele havia recém-terminado, no final de 1944, várias tarefas: o Padre Jesuíno do Monte Carmelo; um ensaio sobre Portinari; a monografia sobre a pintura de Clóvis Graciano; o artigo sobre a escultura de Bruno Giorgi, para a Revista Acadêmica; a revisão das provas dos primeiros livros para as suas Obras completas da Livraria Martins. Desgostara-se com a edição de Belazarte não-revisada pela AmericEdit e angustiava-se também por causa de uma dívida grande, contraída com a compra do Sítio Santo Antônio, em São Roque, em que havia os restos da capela do tempo das bandeiras.

Observe-se que, para recompor esses dias que antecederam a morte de Mário de Andrade, Marcos de Moraes recorreu a diversas fontes: a correspondência do próprio escritor (com Moacir Werneck de Castro, Murilo Miranda, Rodrigo Mello Franco de Andrade e Francisco Iglesias), cartas entre seus amigos (por exemplo, de Oneyda Alvarenga a Henriqueta Lisboa), uma entrevista e um depoimento do secretário e amigo José Bento Faria Ferraz, além de matérias de periódicos da época (da Coleção Carlos Alberto Passos, IEB-USP).

Assim, as primeiras páginas de $O r$ gulho de jamais aconselhar sintetizam a partir da morte a trajetória de um escritor comprometido com a arte nos pla- 
nos estético e social - com as exigências de sinceridade, conhecimento técnico e consciência ante as angústias do tempo. ${ }^{1} \mathrm{O}$ ímpeto narrativo dessas páginas iniciais, capazes de despertar comoção, e sua preocupação documental e formativa já revelam a força crítica que marca o livro. Tal força decorre de Marcos de Moraes combinar a paixão de leitor com o espírito consciencioso de pesquisador. O entusiasmo pela obra epistolográfica de Mário de Andrade se impõe ao crítico, porque ela fala aos problemas de seu tempo, de sua profissão e universais - como os dilemas da amizade, da identidade brasileira e da crítica literária, tão flagrantes no momento atual, em que são raros os valores éticos e artísticos. Ao mesmo tempo, o entusiasmo é formador, ao exercer-se como trabalho paciente de pesquisa, dedicado a recolher as informações necessárias para a compreensão de um intelectual e artista tão múltiplo.

Se já se adivinha, como valor do texto de Marcos, o sentido ético da crítica proposto por Mário de Andrade, isso se confirma na seqüência, na análise de "Atualidade de Chopin". Deixando ver seus próprios passos críticos, Marcos de Moraes pondera que Mário elaborou a biografia de Chopin por identificar-se com um homem que realizou "o sentido humano social" da arte. Marcos depreende, do mirar-se em Chopin, o ideal estético e ético de Mário: o artista íntegro é o insatisfeito, o inconformista, que trabalha arduamente em sua criação e transfere "para uma vida ideal o quanto ambiciona para a vida real" (p.18).

$\mathrm{Na}$ seqüência do primeiro capítulo, entende-se seu título, "Persona, Personagens": numa atitude inconformista, Marcos de Moraes busca desmistificar a imagem de Mário como mestre sem dilemas, criada a partir de discursos grandiloqüentes de despedidas escritos quando da morte do escritor. Se o estudo da correspondência possibilitaria compreender-lhe melhor a figura complexa, a concepção de arte e o papel na cultura brasileira como crítico, criador, pesquisador e formador de jovens, o ensaio "Suas cartas", de março de 1944, de Carlos Drummond de Andrade, foi o primeiro a revelar a amplitude do projeto epistolar de Mário e de seus desdobramentos. Citando Moacir Werneck de Castro, Marcos nega a imagem simplista de um Mário de Andrade bonzinho que distribuísse olimpicamente sabedoria aos moços: desvela que sua atitude nas cartas era a do amigo solícito e crítico severo, pautava-se pelo "culto da solidariedade" e o "virtuosismo ético". Tratava-se de uma "troca fecundante", em que a "generosidade interessada" de Mário recebia um "acréscimo de riqueza interior" (p.58-9).

É interessante que Marcos realça o prenúncio de Antonio Candido nos anos 1940: segundo esse, ao virem à tona, as cartas de Mário permitiriam delinearse um painel da "ação subterrânea" do mentor sobre as consciências jovens de seu tempo. Candido ressaltava que, para Mário, a inteligência deveria revelar a beleza e servir ao próximo e, portanto, escrever cartas era uma "responsabilidade moral e literária" como escrever poemas e estudos (p.64).

Do segundo capítulo ("Auto-retrato, mise-en-scènes") destacam-se, em princípio, a consciência de Mário de Andrade quanto à especificidade da escrita epistolar e a preocupação com sua aparente falsidade. Reconhecendo na epistolografia a tênue fronteira entre o prosaico e o 
literário e a tendência à mise-en-scène, o escritor teme a literatice e concebe necessária a sinceridade das cartas.

Então, contra a imagem congelada do "mestre", Marcos de Moraes apreende algumas das várias faces epistolares da mise-en-scène de Mário: a "reverência construída" para Tarsila do Amaral, a orientação do "professor" de Oneyda Alvarenga, o "fraterno distanciamento" em relação a Anita Malfatti, o "dilacerante confessionário" para com Henriqueta Lisboa.

O profundo conhecimento de Marcos sobre as cartas de Mário de Andrade faz dele um narrador privilegiado da biografia do escritor, conforme já se notou quanto à reconstituição dos dias anteriores à morte de Mário. Nesse sentido, sobressaem outras passagens do livro, como a história da amizade com Anita Malfatti ("Irmã suavíssima"): incluiu o ilimitado da união de almas sacrificadas às artes; os limites de "amor e medo"; os impasses entre proximidade e distância, de um mentor grato à pintora apaixonada que lhe revelara as vanguardas e a quem indicou depois a preocupação com a identidade brasileira e com uma forma de figurá-la.

Muito relevante é a correspondência com Manuel Bandeira, organizada e publicada por Marcos de Moraes (Andrade \& Bandeira, 2000). Espaço de criação garantido pela camaradagem, abriu-se para o confronto de idéias e a superação de suscetibilidades, com o propósito de que os textos do outro ficassem excelentes. Bandeira era o alterego ideal de Mário: verdadeira, a amizade deles se singulariza como exemplo de crítica franca e cooperação literária. Como aponta Marcos, as cartas representam "arquivos da criação": permitem acompanharem-se o en- gendramento de um texto, até suas motivações externas, e seu desenvolvimento partilhado com amigos (por exemplo, as reflexões de Mário e de Bandeira a partir das objeções do primeiro ao poema "Debussy", e do segundo à "Carta pras Icamiabas"). Já se percebe constituírem as cartas, além de espaço de experimentação, o "laboratório da crítica", e nesse sentido Marcos evoca uma carta de Mário de Andrade a Otávio de Faria, de 1927, centrada em Mundos mortos.

Nas confidências dolorosas a Henriqueta Lisboa, a carta funciona como espaço de terapêutica psicanalítica. Sobretudo no início dos anos 1940, Mário demonstra consciência de que, ao escrever para a amiga poeta, dá forma ao caos de suas angústias. Note-se que Marcos de Moraes rastreia a presença da psicanálise nas cartas do escritor, com destaque para o seu uso na interpretação de "seqüestros" na poesia de Drummond em 1930 e para a rejeição da psicanálise em 1942, por considerar que ela reduz a generalizações o mundo imenso do ser humano.

Em seu projeto sobre o folclore nacional, Mário de Andrade se correspondia com Câmara Cascudo. Conforme a análise atenta de Marcos, Mário, em carta de 1928, com uma linguagem próxima da fala e da vivência do outro, com alusões em especial à "sodade" da viagem a Natal e, assim, apagando vestígios de imposição, persuadiu o folclorista a não interromper seus estudos sobre lendas e tradições brasileiras. Portanto, o carteador se aproximava do interlocutor para proceder à sedução intelectual. E Marcos identifica tal recurso como a "ilusão de presença", o qual integrava o projeto pedagógico da epistolografia de Mário de Andrade. 
Eis que o segundo capítulo se concentra nos componentes didático e biográfico das cartas de Mário, trazendo à luz o dilema do pragmatismo de sua obra. Violão da literatura, exercício anterior ao piano: assim Mário definiu o gênero epistolar como espaço de treino diário com a escrita. Suas cartas incorporavam os torneios graciosos da crônica e o movimento narrativo do conto. Quando voltadas para o ensino, aprofundavam temas, incitavam reações e procuravam instaurar a dúvida, sempre num tom de simplicidade. A autoridade intelectual de Mário impunha-se porque, preocupado com a formação de artistas e de cidadãos, ele lia atenciosamente os poemas e romances que os jovens lhe enviavam e partilhava com eles não só o saber sem pedantismo, como também as indecisões da vida.

Mas a epistolografia contém muito de testemunho autobiográfico e memória, e escrever para o outro é, a um tempo, escrever para si mesmo. Atento à produção material das cartas de Mário de Andrade, Marcos, perspicaz, a vê indissociável do seu conteúdo afetivo. Tamanho o apego à companheira máquina de escrever, adquirida em 1925, Mário a chamou de Manuela, em homenagem ao amigo Bandeira. Contudo, nos anos 1940, experienciados os sofrimentos no Departamento de Cultura, passou a preferir a escrita lenta, nascida de sua mão.

Então, na década de 1940, Mário se preocupou com a possibilidade de se tornar pública sua extensa epistolografia, contraditória e reveladora de intimidades. A interpretação de Marcos de Moraes ilumina a duplicidade da formulação poética de Mário "Ao sol / Carta é farol", de 1945: se o papel positivo da carta consiste em orientar como um farol, é indesejável ostentar a todos um conteúdo particular, que deveria permanecer submerso.

Ao reavaliar o procedimento pedagógico de suas cartas, o poeta nega à produção epistolar qualquer veleidade de permanência literária: a escrita conforme o fluxo do pensamento, expondo saberes e incitando dúvidas, indica que lhe interessara, desde os tempos do modernismo, servir como professor às novas gerações. Como salienta Marcos de Moraes, desde as correspondências de propagação do ideário modernista, Mário criou uma rede de comunicação até então nunca vista na história literária brasileira, a qual incluía literatos, pintores, músicos, fossem grandes ou medíocres.

E Marcos seleciona uma carta de 1934 ao ensaísta português José Osório, em que, para se contrapor ao conformismo desse, Mário enfatizava suas posturas de sacrifício pragmático: dentre outras, o pacifista do livro de estréia; o desvairista de 1922, comprometido com a vanguarda européia; o nacionalista inventor da língua literária brasileira; o musicólogo pioneiro em elaborar no Brasil uma história da música; enfim, o crítico empenhado sempre em ser útil. Assim, como artista e pensador, incluindo por meio da epistolografia, num esforço antiindividualista, procurou servir à construção de uma autêntica cultura brasileira. Repare-se que o projeto epistolar de caráter didático surgira em 1924, com a proposta nacionalista, em especial ante o ceticismo de Drummond. Cumpria aos escritores avaliarem criticamente as idéias importadas e buscarem a identidade cultural brasileira, para então atingirem universalidade; mas era também necessário configurar esteticamente esse material segundo as formas modernas. 
No fim do segundo capítulo, ao tratar da organização da Série Correspondência de Mário de Andrade do Arquivo do IEB-USP, Marcos sintetiza terem sido as cartas alimento para as várias áreas de atuação do escritor modernista: a criação, a crítica, o estudo do folclore. E anuncia ao leitor que está dedicado a um instigante trabalho com o manuscrito inédito de $O$ pico dos três irmãos, esboço de um ensaio de Mário sobre a poesia de Bandeira, Drummond e Murilo Mendes.

No início do terceiro capítulo ("Uma áspera pedagogia"), partindo de uma carta a Bandeira de 1925, em que Mário esboçou um auto-retrato de sua mocidade, Marcos de Moraes traça o "Retrato do carteador quando jovem". Aqui, ao se confirmar a importância da epistolografia como fonte para se compreender a vida de Mário de Andrade, insinua-se como horizonte de Marcos a necessária biografia intelectual do escritor. Com base na cronologia de $A$ imagem de Mário: fotobiografia de Mário de Andrade, preparada por Telê Ancona Lopez, ele tece a construção biográfica da mocidade de Mário, de que ressaltam: as leituras do primeiro ano (1910) na Faculdade de Filosofia e Letras de São Paulo (Verhaeren, Claudel, Francis Jammes, Bergson etc.); os estudos de piano, canto e história da música no Conservatório Dramático Musical de São Paulo, de 1911 a 1917, quando assume a cadeira de professor; o luto pela morte do irmão em 1913; o primeiro livro e o encontro com Anita Malfatti em 1917; a Semana de Arte Moderna em 1922, aos trinta anos.

Na seção "Drácula e os moços", Marcos de Moraes traz elementos para se entenderem a concepção de arte e de crítica de Mário e, portanto, os sofrimentos por ele vividos nos anos 1940, quando foi incompreendido. Afligiu-se ao ver distorcida sua ação pedagógica: o jornalista José César Borba, que pregava a neutralidade da arte em relação à guerra, acusava-o entre os "Mestres Dráculas" decadentes. Também artigos não-assinados da revista carioca Dom Casmurro (que tinha Jorge Amado como redatorchefe) o apontavam como mestre decaído, que teria voltado à torre de marfim. Como mostra Marcos, esses dois artigos não-assinados fizeram parte de uma polêmica que incluiu os ensaios "A palavra em falso" e "A raposa e o tostão", de Mário, "O tostão e o milhão", de Joel Silveira, e, por fim, "Os tostões do Sr. Mário de Andrade", de Graciliano Ramos. Se concordavam todos eles quanto a viverem uma fase de livros ruins, Graciliano defende o rigor crítico ao apontar o perigo da total perda de valores, de se chamarem bons escritores como Joel Silveira injustamente de tostões.

Essa polêmica ajuda a formar um conceito de arte e a reconhecer os impasses e realizações artísticas da literatura brasileira desde o movimento modernista. No tempo do estreito formalismo parnasiano, Mário lutara pela liberdade da técnica. Porém, ao se generalizarem as conquistas do modernismo, à medida que a extravagância, a facilidade, a falta de disciplina adentraram a arte, ele passou a combater pela necessidade de consciência técnica do artista. Ao mesmo tempo, ante a Segunda Guerra, enfatizou o sentido social da arte, "força interessada na vida", inconformista. Por isso, diante de construções literárias frágeis e apressadas dos estreantes, apontava-as sem se apiedar, confiante no potencial de superação moral e estética próprio da busca de técnica. Assim, defendia a conjugação das faces estética e pragmática da arte, não exclusivas. 


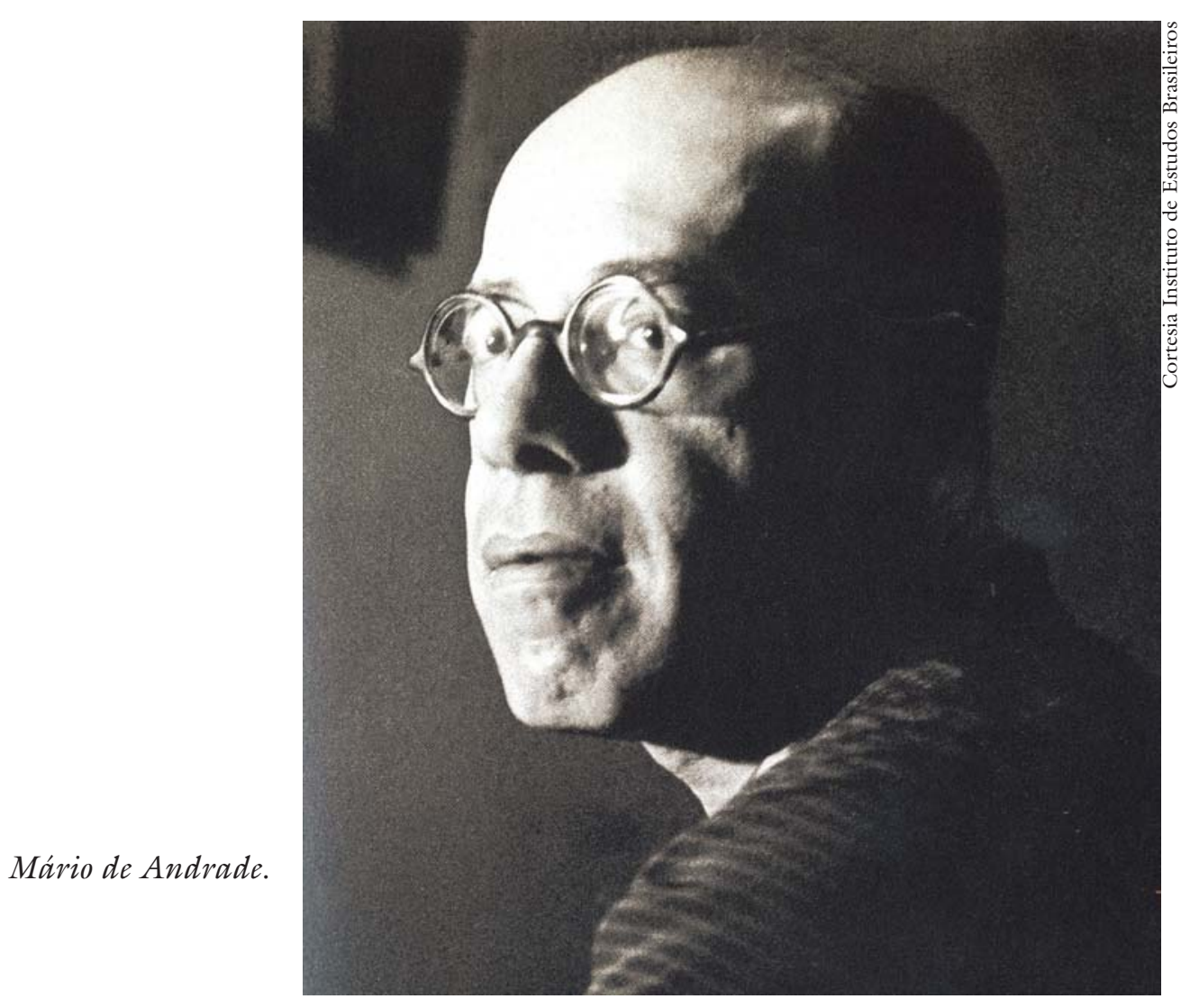

Marcantes na trajetória didático-epistolar de Mário de Andrade, Marcos destaca figuras como: José Antonio Ferreira Prestes, Fernando Mendes de Almeida, Camargo Guarnieri, José Bento Faria Ferraz, Fernando Sabino, Gilda Rocha (Gilda de Mello e Souza), Oneyda Alvarenga. Mário queria muito bem a esses amigos e, fundado no sentido de responsabilidade da amizade, não admitia que não o procurassem como orientador de estudos. Sofreu muito com o suicídio do moço José Antonio Ferreira Prestes: culpava-se de não o haver ajudado o suficiente e confiava em sua potencialidade como crítico musical. "Professor" apaixonado pelo que ensinava e responsável pelos amigos, Mário desgostou-se porque Fernando Mendes de Almeida não se abriu ao diálogo formador e publicou livros precários.
Para Mário de Andrade, a carta era o espaço privilegiado para a celebração da amizade: buscava uma linguagem nãocerimoniosa, útil para o convencimento intelectual, e desejava um diálogo sem o temor de melindres. Em seu projeto pedagógico, que carregava um sentido formativo de (auto)crítica, tinha consciência do poder corrosivo ou fecundante de suas palavras. Receptivo à influência do professor, Camargo Guarnieri reconheceu a contribuição dele para seu desenvolvimento artístico: beneficiara-se desse diálogo que, contrário à autocomplacência, revelava a necessidade de superação. Bela crônica de amizade e profissionalismo, merece a atenção de Marcos de Moraes também a correspondência com o secretário José Bento Faria Ferraz, rica em dados biográficos e em rastros da produção intelectual de Mário. 


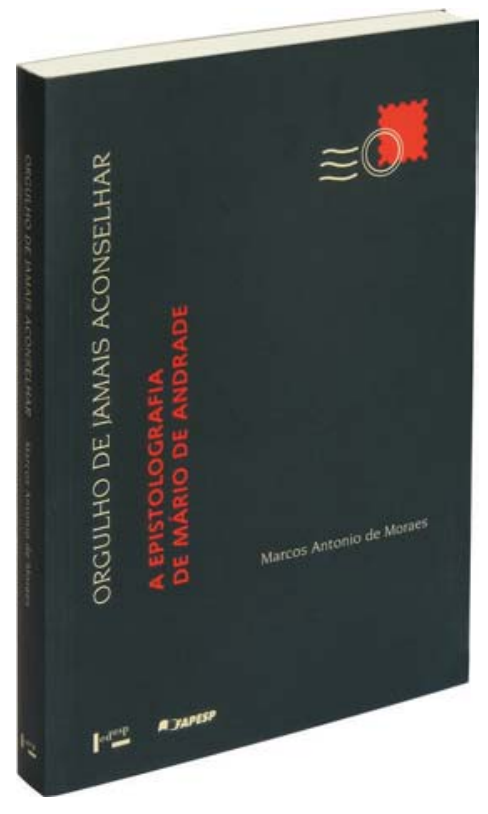

MORAES, Marcos Antonio de.

Orgulbo de jamais aconselhar:

a epistolografia de Mário de Andrade.

São Paulo: Edusp; Fapesp, 2007. 245p.

Fernando Sabino também aprendeu muito com o mestre: esse lhe indicou "leituras imprescindíveis para a dignidade do intelectual" e diretrizes de escritor, como a sinceridade de expressão artística e a participação nas questões do tempo e do país. Além disso, leitor exigente dos contos de Sabino, garantiu-lhe que só os bons suportam a crítica severa. Igualmente Gilda de Mello e Souza recebeu a influência do primo, que lia e comentava tudo o que ela escrevia. Segundo Gilda, interessavam a Mário a busca da verdade e a partilha desse caminho com os outros, sobretudo com os jovens, por meio da correspondência. Não the bastava acumular erudição: precisava refletir sobre o saber e compartilhar essas reflexões. Nesse sentido, Marcos de Moraes recorda uma longa carta a Oneyda Alvarenga, escrita entre 14 e 21 de se- tembro de 1940. Nela, Mário se centrava na questão da necessidade ou não de conhecimento técnico de uma arte para compreender-lhe as obras. E Marcos oferece ao leitor, como anexo do livro, uma instigante "Normativa da crítica", esquema para a reflexão sobre o ofício da crítica, enviado pelo escritor em 1941 para Luís Saia e depois para Moacir Werneck de Castro.

Dessa forma, estudando com entusiasmo e minúcia a epistolografia de Mário de Andrade, Marcos de Moraes desvela a dedicação apaixonada do escritor à formação intelectual e artística dos jovens: lia e comentava os textos deles com severidade, incitando a dúvida, rejeitando a subserviência e abrindo-se ao diálogo e à partilha de seu saber e experiências. Com sua "generosidade interessada" de educador, criticava problemas estéticos e condutas de vida; entretanto, o prazer de ser útil era carregado de dilemas.

No capítulo final, "Orgulho de jamais aconselhar", Marcos explicita esse dilaceramento da pedagogia de Mário: ele evitava o tom de conselho, que, denotando inferioridade do outro, poderia tornar infecunda a vocação dos interlocutores moços. Conforme ressalta Marcos, é evidente que o conselho subsistia, porém escondido nas "fissuras da escrita epistolar que amealha volúpia analista e temor do tom professoral de quem não tem 'a veleidade de decidir de todos os problemas humanos"” (p.221). Nesses versos de Drummond, reencontra-se o gosto de Mário pelo dilaceramento de mentor intelectual dos jovens: professor interessado sempre pela vida, seu "ensino cantante" persevera para além da morte, "martelo / a vibrar no verso e na carta: / A própria dor é uma felicidade" (Andrade, 1964b, p.340). 
Assim, a complexa pedagogia realizada na epistolografia de Mário de Andrade pressupunha e propunha a necessidade de conhecimento técnico, a atitude inconformista e a busca de compreensão crítica de si e dos outros. Já se reconhecem aí os planos estético e ético da concepção de arte do escritor. E o livro de Marcos de Moraes tem vários méritos: revela, por meio das cartas do poeta modernista, esses sentidos de arte e de crítica autênticos, apreendendo os rastros de sua criação, reflexão crítica e trabalho intelectual. Ao mesmo tempo, delineia o perfil biográfico de Mário e, juntamente, resgata as figuras de importantes artistas e intelectuais brasileiros. Completam a obra uma lista dos livros de correspondência da biblioteca de Mário e uma bibliografia muito útil, que abrange o gênero epistolar, o modernismo e a obra do escritor, incluindo cartas publicadas em periódicos, esparsas em livros e inéditas. Na contracapa do livro, a letra de Mário, na referida carta a Oneyda Alvarenga, confirma-o interessado sempre em servir aos outros, em busca da compreensão da arte.

Enfim, seguindo o roteiro algo didático que tracei do livro, convido, fecunda inquietação paradoxal, ao Orgulho de jamais aconselhar: a compreensão da vida e da arte de Mário de Andrade por meio de suas cartas.

\section{Nota}

I Para Mário de Andrade (1972), a arte é conjugação de estética e interesse pela vida; a busca da verdade absoluta do artista, de superação, inclui a técnica pessoal, plena de "potência moralizadora", e o "pensamento inconformável aos imperativos exteriores".
Referências bibliográficas

ANDrade, C. D. de. Mário de Andrade desce aos infernos (A rosa do povo). In: Obra completa. Rio de Janeiro: Aguilar, 1964a. p.211.

Mário longínquo (Lição de coisas). In: _. Obra completa. Rio de Janeiro: Agilar, 1964b. p.340.

ANDRADE, M. de. A elegia de abril (1941); O movimento modernista (1942). In:

Aspectos da literatura brasileira. 4.ed. São Paulo: Martins; Brasília: INL, 1972.

ANDRADE, M. de; BANDEIRA, M. Correspondência Mário de Andrade \& Manuel Bandeira. Organização, introdução e notas de Marcos Antonio de Moraes. São Paulo: Edusp; IEB, 2000.

Ieda Lebensztayn é doutoranda em Literatura Brasileira na Faculdade de Filosofia, Letras e Ciências Humanas da Universidade de São Paulo, bolsista da Fapesp. @ - biolito@gmail.com 